\title{
RESPONSIVENESS MEASUREMENT OF ReConfigurable Manufacturing System
}

\author{
MitTAL, K. K. \& JAIN, P. K.
}

Abstract: Reconfigurable manufacturing systems (RMS) are considered as manufacturing systems that are capable of providing the exact functionality and capacity as and when desired. Volatility of demand, requirement of variety of products, quick development in product and process technology has forced the manufacturing systems to become accustomed the changing requirements efficiently. There are various performance measures like ramp-up time, cost, reliability, availability, lead time, reconfiguration time etc. that affects performance of the reconfiguration manufacturing system. This chapter focuses on the performance measures like reconfiguration time, reconfiguration reliability and the way to find the responsiveness of reconfigurable manufacturing system.

Key words: Reconfigurable manufacturing systems, reconfiguration time, reliability, responsiveness, performance measures
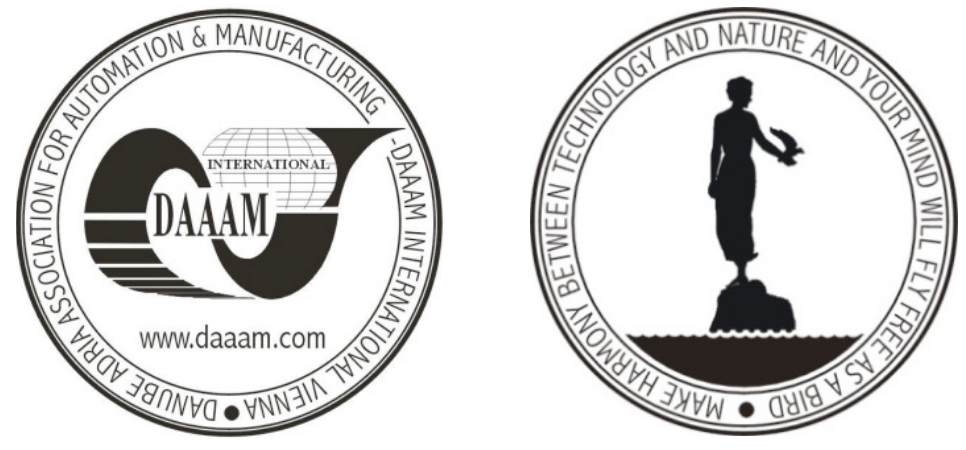

Authors' data: Research Scholar Mittal, K[amal] K[umar]; Prof. Jain, P[ramod] K[umar], Mechanical \& Industrial Engineering Department, IITRoorkee, Roorkee, INDIA, km1900@rediffmail.com, pjainfme@iitr.ernet.in

This Publication has to be referred as: Mittal, K[amal Kumar] \& Jain, P[ramod] [Kumar] (2014). Responsiveness Measurement of Reconfigurable Manufacturing System, Chapter 30 in DAAAM International Scientific Book 2014, pp.373-382, B. Katalinic (Ed.), Published by DAAAM International, ISBN 978-3-901509-98-8, ISSN 1726-9687, Vienna, Austria

DOI: $10.2507 /$ daaam.scibook.2014.30 
Mittal, K. K. \& Jain, P. K.: Responsiveness Measurement of Reconfigurable Manu...

\section{Introduction}

In the manufacturing industry, some of the challenges faced by manufacturers include reducing the lead time, increasing the quality, providing variety of products. Although dedicated manufacturing lines (DMLs) the traditional manufacturing system are capable of producing the similar products in bulk but are incapable of accommodating the product variety. On the other side, Flexible manufacturing system (FMSs) are capable of accommodating the product variety but in comparison to DML the productivity is low (Mehrabi \& Ulsoy,2000; Katalinic et al.,2012). Besides that the cost of FMSs are very high and therefore have very limited acceptability among the manufacturers (Gupta et al.,2012;Mehrabi et al.,2002; Mittal \& Jain,2014). Reconfigurable manufacturing systems (RMS) a new type of manufacturing system has the capability to adjust both capacity and functionality in order to cope up with product variety and production volume (Chao et al., 2010, ElMaraghy, 2006a; Goyal et al., 2012). The overall vision of reconfigurable manufacturing systems (RMSs), as systems of equipment, having a modular structure, that have customized flexibility so one can easily reconfigure the entire system to produce a family of products at different production volumes. Koren \& Ulsoy,(1997); Koren,(2013) was the first to describe how the system configuration has a significant impact on the performance of the RMS in terms of throughput and quality. Koren \& Ulsoy,(1997); Koren,(2013) described the effects of system configurations for RMS sand concluded that parallel configurations with cross-over yield significant benefits in throughput, performance and scalability when identical machines are used throughout the system. Other publications such as (ElMaraghy,2006b; Alejandro et al.,2013) discuss various method of making capacity decisions for reconfigurable manufacturing systems taking into account issues such as equipment selection, multipart production, and stochastic demand. However, little focus has been given on the modularity of Reconfigurable Machine Tool (RMT). RMS having its core component Reconfigurable Machine Tool (RMT).The Reconfigurable Machine Tools are developed as modular machines having different modules (Koren,1999; Koren,2005; Galan et al.,2007;Goyal et al.,2011).The RMTs having basic and auxiliary modules. The basic modules are such as base, slide ways and auxiliary modules are such as spindle heads, tool changer which are relatively smaller and lighter than the basic modules. The auxiliary module can be quickly and easily changed with minimum effort. By adding or removing the RMTs can be reconfigured into many other configurations (Koren et al.1998; Youssef\& ElMaraghy,2006; Youssef\& ElMaraghy,2007; Goyal et al.,2011). Figure 1 shows the configuration of RMTs from the standard module library, in which two machine configurations of a machine are assembled by just varying the auxiliary modules. The detailed analysis of module interactions at the machine level has not been considered in most of the RMS models, which is the key enabler of responsiveness of RMS.Because of this, importance of the present study is on the development of responsiveness measure at the machine level which would definitely reduce the reconfiguration efforts required at various levels in the later stage. 


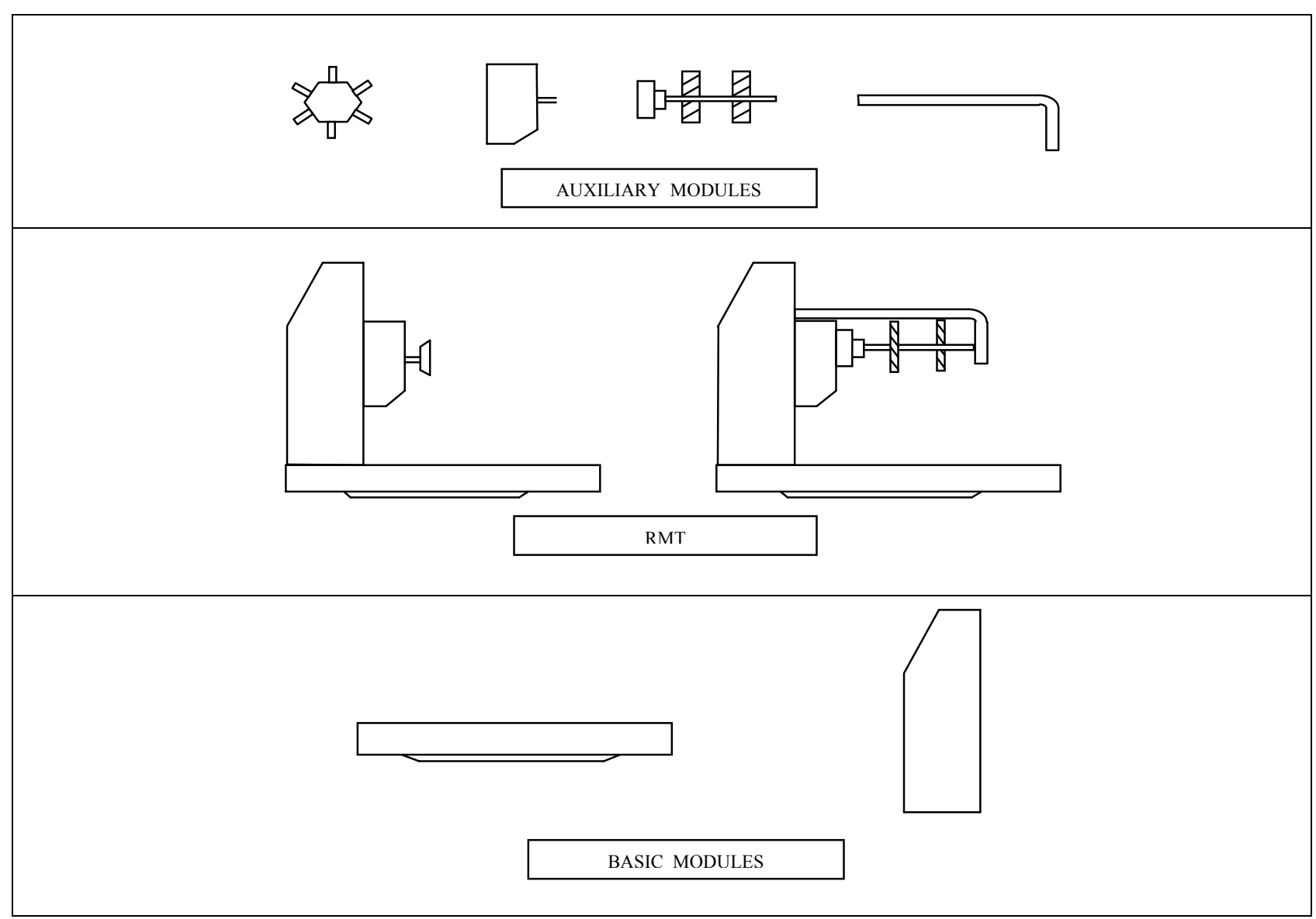

Fig. 1. RMT's configurations from standard module library

\section{Requisite of the performance measure}

Reconfiguring the system components over the time for a diverse set of individualized products often required in small quantities and with very short delivery lead time. This necessitates the requirement of mapping the manufacturing system capabilities and other characteristics by developing a suitable performance measure. To measure the performance of RMS, their various core characteristics such as modularity, scalability, convertibility and diagnosability should be considered (Gumasta,2011; Mittal \& Jain,2014). In most of the RMS modeling, the reduction in cost and reconfiguration effort is considered an objective. Many researchers have addressed the problem in two phases. In the first phase, solutions are recorded for each stage based on cost as a criterion. In the subsequent stage, the best alternatives are chosen from the previously recorded alternatives for each time horizon based on the objective to minimize the reconfigurations required at various stages (ElMaraghy\& Deif 2006; Goyal et al.,2012). A new manufacturing paradigm, called Reconfigurable Manufacturing Systems (RMSs) is designed for rapid adjustment of production capacity and functionality, in response to new circumstances, by rearrangement or change of its components. These new systems provide exactly the functionality that is needed, exactly when it is needed (Mehrabi \& Ulsoy,2000). Therefore, a RMS is designed to be easily reconfigured such that it is able to process a family of parts and accommodate new and unanticipated changes in the product 
Mittal, K. K. \& Jain, P. K.: Responsiveness Measurement of Reconfigurable Manu...

design and processing needs. The utility of a RMS is greatly increased if it is highly responsive in nature.The responsiveness is dependent on various performance measures like reconfiguration time and reconfiguration reliability. The measurement of responsiveness can be calculated by calculating reconfiguration time, reconfiguration reliability etc. The benefits of configurability include economies of scale, increased feasibility of product / component change, increased product variety, and reduced lead time (Yigit \& Allahverdi,2003).

\section{Reconfiguration time}

Reconfiguration time is the time taken in changing one configuration to another configuration. The time includes adding, removing and readjusting the modules. Tab. 1 gives different machine configurations with their basic and auxiliary modules.

\begin{tabular}{|l|l|l|}
\hline Machine configurations & Basic Module(BM) & Auxiliary Modules(AM) \\
\hline $\mathrm{mc}_{1}{ }^{1}$ & $(\mathrm{a}, \mathrm{b})$ & $(\mathrm{c}, \mathrm{d}, \mathrm{e})$ \\
\hline $\mathrm{mc}_{1}{ }^{2}$ & $(\mathrm{a}, \mathrm{b})$ & $(\mathrm{e}, \mathrm{g}, \mathrm{h})$ \\
\hline $\mathrm{mc}_{1}{ }^{3}$ & $(\mathrm{a}, \mathrm{b})$ & $(\mathrm{c}, \mathrm{d}, \mathrm{g}, \mathrm{f})$ \\
\hline
\end{tabular}

Tab. 1. Basic and Auxiliary module for different machine configurations

Tab. 2 gives the reconfiguration time in adding the auxiliary module from one configuration to another.

\begin{tabular}{|l|l|l|l|l|l|l|}
\hline $\begin{array}{l}\text { Module } \backslash \text { Reconfiguration } \\
\text { time }\end{array}$ & 12 & 23 & 31 & 21 & 32 & 13 \\
\hline $\mathrm{c}$ & - & 1 & - & 1 & - & - \\
\hline $\mathrm{d}$ & - & 3 & - & 1 & - & - \\
\hline $\mathrm{e}$ & - & - & 4 & & 2 & - \\
\hline $\mathrm{f}$ & - & 4 & - & - & - & 4 \\
\hline $\mathrm{g}$ & 6 & - & - & - & - & 4 \\
\hline $\mathrm{h}$ & 6 & - & - & - & 6 & - \\
\hline
\end{tabular}

Tab. 2. Reconfiguration time (sec) when adding the Auxiliary module

NRAT (Normalized Reconfiguration addition time) for different auxiliary module is given by

$$
\mathrm{NRAT}=\alpha \mathrm{mc}_{\mathrm{ij}}+\beta \mathrm{mc}_{\mathrm{pq}}
$$

where $\alpha \& \beta$ are the weights assigned $(\alpha+\beta=1)$ and $i, j, p, q=1,2,3$ and the assumed value of $\alpha \& \beta$ are 0.5.E.g. for auxiliary module c, $\mathrm{NRAT}_{\mathrm{c}}=\alpha \mathrm{mc}_{23}+\beta \mathrm{mc}_{21}=$ $(1+1) / 2=1$ 
Similarly Normalized Reconfiguration addition time for different auxiliary modules can be calculated and listed in Tab. 5 .

Tab. 3 gives the reconfiguration time in removing the auxiliary module from one configuration to another.

\begin{tabular}{|l|l|l|l|l|l|l|}
\hline $\begin{array}{l}\text { Module } \backslash \text { Reconfiguration } \\
\text { time }\end{array}$ & 12 & 23 & 31 & 21 & 32 & 13 \\
\hline c & .5 & - & - & - & .5 & - \\
\hline d & 1 & - & - & - & 1 & - \\
\hline e & - & 2 & - & - & - & 1 \\
\hline f & - & - & 1 & - & 3 & - \\
\hline g & - & - & 2 & 3 & - & - \\
\hline h & - & 4 & - & 2 & - & - \\
\hline
\end{tabular}

Tab. 3. Reconfiguration time (sec) when removing the Auxiliary module

NRRT (Normalized Reconfiguration removal time) for different auxiliary module is given by

$$
\mathrm{NRRT}=\boldsymbol{\sigma} \mathrm{mc}_{\mathrm{ij}}+\Omega \mathrm{mc}_{\mathrm{pq}}
$$

where $\sigma \& \Omega$ are the weights assigned $(\sigma+\Omega=1)$ and i, j, p, q=1, 2, 3 and the assumed value of $\boldsymbol{\sigma} \& \Omega$ are 0.5.E.g. for auxiliary module c, $\mathrm{NRRT}_{\mathrm{c}}=\boldsymbol{\sigma} \mathrm{mc}_{12}+\Omega$ $\mathrm{mc}_{32}=0.5$

Similarly Normalized Reconfiguration removal time for different auxiliary modules can be calculated and listed in Tab. 5 .

Tab. 4 gives the reconfiguration time in readjusting the auxiliary module from one configuration to another.

\begin{tabular}{|l|l|l|l|l|l|l|}
\hline Module $\backslash$ Rec. time & 12 & 23 & 31 & 21 & 32 & 13 \\
\hline $\mathrm{c}$ & - & - & 0.8 & - & - & 0.6 \\
\hline $\mathrm{d}$ & - & - & 1.2 & - & - & 1.8 \\
\hline $\mathrm{e}$ & 2.5 & - & - & 1.5 & - & - \\
\hline $\mathrm{f}$ & - & - & - & - & - & - \\
\hline $\mathrm{g}$ & - & 2 & - & - & 2 & - \\
\hline $\mathrm{h}$ & - & - & - & - & - & - \\
\hline
\end{tabular}

Tab. 4. Reconfiguration time (sec) when readjusting the Auxiliary module

NRReT (Normalized Reconfiguration readjustment time) for different auxiliary module is given by

$$
\mathrm{NRReT}=\mu \mathrm{mc}_{\mathrm{ij}}+\partial \mathrm{mc}_{\mathrm{pq}}
$$

where $\mu \& \Omega$ are the weights assigned $(\mu+\partial=1)$ and $i, j, p, q=1,2,3$ and the assumed value of $\mu \& \partial$ are 0.5.E.g. for auxiliary module $\mathrm{c}, \mathrm{NRReT}_{\mathrm{c}}=\mu \mathrm{mc}_{12}+\partial$ $\mathrm{mc}_{32}=0.7$ 
Mittal, K. K. \& Jain, P. K.: Responsiveness Measurement of Reconfigurable Manu...

Similarly Normalized Reconfiguration readjustment time for different auxiliary modules can be calculated and listed in Tab. 5 .

Tab. 5 gives the normalized value of reconfiguration time in adding, removing and readjusting the auxiliary module from one configuration to another.

\begin{tabular}{|c|c|c|c|}
\hline $\begin{array}{c}\text { Auxiliary } \\
\text { Modules }\end{array}$ & $\begin{array}{c}\text { Reconfiguration time } \\
\text { when adding the } \\
\text { module }\end{array}$ & $\begin{array}{c}\text { Reconfiguration time } \\
\text { when removing the } \\
\text { module }\end{array}$ & $\begin{array}{c}\text { Reconfiguration time } \\
\text { when readjusting the } \\
\text { module }\end{array}$ \\
\hline $\mathrm{c}$ & 1 & .5 & .7 \\
\hline $\mathrm{d}$ & 2 & 1 & 1.5 \\
\hline $\mathrm{e}$ & 3 & 1.5 & 2 \\
\hline $\mathrm{f}$ & 4 & 2 & - \\
\hline $\mathrm{g}$ & 5 & 2.5 & 4 \\
\hline $\mathrm{h}$ & 6 & 3 & - \\
\hline
\end{tabular}

Tab. 5. Reconfiguration time (sec) for different Auxiliary module (Normalized value)

Total Reconfiguration Time(TRT) can be calculated as follows

$$
\mathrm{TRT}_{\mathrm{ij}}=\left(\begin{array}{c}
\left(\mu \frac{\text { time in adding the module }}{\text { Total available time }}+\Omega \frac{\text { time in removing the module }}{\text { Total available time }}+\right. \\
\left.\sigma \frac{\text { time in readjusting the module }}{\text { Total available time }}\right)
\end{array}\right.
$$

where $\mathrm{i}, \mathrm{j}=1,2,3$; and the assumed value of different weights are $\mu=.5, \Omega=.4, \sigma=.1$ and Total available time $=20 \mathrm{sec}$

The modules added are $\mathrm{g}$ and $\mathrm{h}$, the modules removed are $\mathrm{c}$ and $\mathrm{d}$ and the modules readjusted are $\mathrm{e}$ in changing configuration 1 to 2.Hence Total Reconfiguration Time $\left(\mathrm{TRT}_{12}\right)=.5(5+6) / 20+.4(1.5) / 20+.1(2) / 20=.315$

Similarly Total Reconfiguration Time for $\mathrm{TRT}_{13}, \mathrm{TRT}_{23}, \mathrm{TRT}_{32}, \mathrm{TRT}_{31}$ and $\mathrm{TRT}_{21}$ can be calculated and listed in Tab. 6 .

\begin{tabular}{|l|l|l|}
\hline S.No. & Total Reconfiguration Time & Results \\
\hline 1. & $\mathrm{TRT}_{12}$ & 0.315 \\
\hline 2. & $\mathrm{TRT}_{13}$ & 0.266 \\
\hline 3. & $\mathrm{TRT}_{23}$ & 0.285 \\
\hline 4. & $\mathrm{TRT}_{32}$ & 0.315 \\
\hline 5. & $\mathrm{TRT}_{31}$ & 0.176 \\
\hline 6. & $\mathrm{TRT}_{21}$ & 0.195 \\
\hline
\end{tabular}

Tab. 6. Total Reconfiguration time 


\section{Reconfiguration reliability}

Reconfiguration reliability is the reliability in changing one configuration to another configuration. The reliability includes adding, removing and readjusting the modules. Tab. 7 gives reliability of basic and auxiliary modules.

\begin{tabular}{|c|c|}
\hline Modules & Reliability(R) \\
\hline Basic Module(BM) & .9 \\
\hline $\mathrm{c}$ & .9 \\
\hline $\mathrm{d}$ & .8 \\
\hline $\mathrm{e}$ & .7 \\
\hline $\mathrm{f}$ & .6 \\
\hline $\mathrm{g}$ & .7 \\
\hline $\mathrm{h}$ & .6 \\
\hline
\end{tabular}

Tab. 7. Reliability for different modules

The machine configurations and their structure is given in Tab. 8 .

\begin{tabular}{|l|l|l|}
\hline $\begin{array}{l}\text { Machine } \\
\text { configurations }\end{array}$ & \multicolumn{2}{c|}{ Structure of modules } \\
\hline $\mathrm{mc}_{1}{ }^{1}$ & & \\
\hline $\mathrm{mc}_{1}{ }^{2}$ & & \\
\hline $\mathrm{mc}_{1}{ }^{3}$ & $\mathrm{BM}$ & $\mathrm{BM}$ \\
\hline
\end{tabular}

Tab. 8. Structure of modules

Reconfiguration Reliability (RR) for different changeover is calulated as below.

$$
(R R)_{i j}=R_{p} x \ldots . . x R_{q}
$$

where $_{i, j}=1,2,3$ and $p, q=B M, c, d, g, h, e, f$ if the moduleds are in series.

$$
(R R)_{i j}=\left[1-\left(1-R_{p}\right) x \ldots \ldots x\left(1-R_{q}\right)\right]
$$


Mittal, K. K. \& Jain, P. K.: Responsiveness Measurement of Reconfigurable Manu...

where $_{i, j}=1,2,3$ and p,q=BM,c,d,g,h,e,f if the moduleds are in parallel.

e.g The Reconfiguration Reliability $\left(\mathrm{RR}_{12}\right)$ can be calculated as below

$\mathrm{RR}_{12}=.9 \times .7 \times .6 \times .7=.2646$

The Reconfiguration Reliability for different changeover is listed in the Tab. 9.

\begin{tabular}{|l|l|l|}
\hline S.No. & Reconfiguration Reliability & Results \\
\hline 1. & $\mathrm{RR}_{12}$ & 0.2646 \\
\hline 2. & $\mathrm{RR}_{13}$ & 0.5702 \\
\hline 3. & $\mathrm{RR}_{23}$ & 0.5702 \\
\hline 4. & $\mathrm{RR}_{32}$ & 0.2646 \\
\hline 5. & $\mathrm{RR}_{31}$ & 0.4536 \\
\hline 6. & $\mathrm{RR}_{21}$ & 0.4536 \\
\hline
\end{tabular}

Tab. 9. Reconfiguration Reliability

\section{Reconfigurable responsiveness index}

Both the performance measures discussed above directly influ-ence theresponsiveness of the RMS. Therefore the Reconfiguration Reliability and Reconfiguration time should be combined together to achive the responsiveness of the RMS.The Reconfigurable Responsiveness Index (RRI) is calculated as follows:

$$
(\mathrm{RRI})_{\text {stage }}=\sigma(\mathrm{RR})+\chi(\mathrm{RT})
$$

where, $\sigma=.8$ and $\chi=.2$, where $\sigma+\chi=1$.

Since the reliability should be higher than reconfiguration time ,hence the values of $\sigma$ is higher than $\chi$.

e.g The Reconfigurable Responsiveness Index (RRI) ${ }_{\text {stage }}$ can be calculated as below in changing one configuration to another.

$\mathrm{RRI}_{12}=.8 \mathrm{xRR}_{12}+.2 \mathrm{xTRT}_{12}=.8 \times 0.2646+.2 \mathrm{x} .315=.2746$

The Reconfigurable Responsiveness Index for different changeover is listed in the Tab. 10.

\begin{tabular}{|l|l|l|}
\hline S.No. & Reconfigurable Responsiveness Index & Results \\
\hline 1. & $\mathrm{RRI}_{12}$ & 0.2746 \\
\hline 2. & $\mathrm{RRI}_{13}$ & 0.5093 \\
\hline 3. & $\mathrm{RRI}_{23}$ & 0.5131 \\
\hline 4. & $\mathrm{RRI}_{32}$ & 0.2746 \\
\hline 5. & $\mathrm{RRI}_{31}$ & 0.3980 \\
\hline 6. & $\mathrm{RRI}_{21}$ & 0.4018 \\
\hline
\end{tabular}

Tab. 10. Reconfigurable Responsiveness Index 
The Reconfigurable Responsiveness Index is given as below $(\mathrm{RRI})_{\text {stage }}=\left(\mathrm{RRI}_{12}+\ldots \ldots \ldots \ldots \ldots \ldots+\mathrm{RRI}_{21}\right) / 6=0.3952$, considering equal importance at each changeover.

Similarly RRI for all stages and RRI for the system can be computed.

\section{Conclusion}

The present work, propose performance measures enabling responsive reconfigurable manufacturing system, shop floor operations. On the shop floor we plan to improve responsiveness on a set of RMT (Reconfigurable Machine Tools). This would enable the system to adjust functionality and capacity according to feedback from demand and market fluctuations. The performance measures of the Reconfigurable manufacturing system gives an indication to choose the configuration in each stage. In the present study the performance parameter reconfiguration time and reconfiguration reliability have been discussed. These performance parameters are helpful in measurment of responsiveness of RMS. In future the authors plan to develop more performance parameter to the manufacturing system. This research gives a baseline for future research on quantifying responsiveness and therefore reconfigurability of reconfigurable manufacturing systems. There are many ways to extend this work in the future. Effects of material handling devices, tools, fixtures, etc. can also be considered in the process of finding the reconfigurability of the system. Furthermore, work can be done on calculating the responsiveness of the entire system.

\section{References}

Alejandro, Armando, Joel (2013). Design, refinement, implementation and prototype testing of a reconfigurable lathe-mill, Journal of Manufacturing Systems, Vol.32, pp. $364-371$

Chao Lv, AiPing Li and Lyon Xu (2010). Research and optimization of reconfigurable manufacturing system configuration based on system reliability, Kybernetes, Vol.39,No. 6, pp.1058-1065

ElMaraghy, H.A. (2006a). Flexible and reconfigurable manufacturing systems paradigms, International Journal of Flexible Manufacturing System, Vol.17, No.4, pp. $261-276$

ElMaraghy (2006b). Investigating optimal capacity, scalability scheduling in a reconfigurable manufacturing system, Int $J$ Adv Manuf Technol, Vol.32, pp. 557562

ElMaraghy, Deif, A. M. (2006).Effect of reconfiguration costs on planning for capacity scalability in reconfigurable manufacturing systems, J. Intell. Manuf. Vol.18,pp. 225-238

Galan, R., Racero, J., Eugia, I., Canca, D. (2007). A methodology for facilitating reconfiguration in manufacturing: the move towards reconfigurable manufacturing systems, International Journal of Advanced Manufacturing Technology, Vol.33, No. 3-4, pp. 345-353 
Mittal, K. K. \& Jain, P. K.: Responsiveness Measurement of Reconfigurable Manu...

Goyal, K.K., Jain, P.K., Jain, M. (2011). Multiple objective optimization of reconfigurable manufacturing system. In: Deep, K., et al. (Eds.), Proceedings of the International Conference on Soft Computing for Problem Solving, AISC 130, pp. 453-460, Springer

Goyal, K.K., Jain, P.K., and Jain, M. (2012). Optimal configuration selection for reconfigurable manufacturing system using NSGA II and TOPSIS, International Journal of Production Research, Vol. 50,No.15,pp. 4175-4191

Gumasta, K. (2011). Developing a reconfigurability index using multi-attribute utility theory, International Journal of Production Research, Vol. 49, No.6, pp. 1669-1683 Gupta, A., Jain, P. K. and Kumar, D.(2012). Availability Modelling of Reconfigurable manufacturing system, DAAAM International Scientific Book 2012, ISBN 978-3-901509-86-5, ISSN 1726-9687, Vienna, Austria pp. 241-254

Katalinic, B. , Pryanichnikov, V.E., Ueda, K. , Kukushkin, I. , Cesarec, P., Kettler, R. (2012). Bionic assembly system: hybrid control structure, working scenario and scheduling, Proceedings of 9th National Congress on Theoretical \& Applied Mechanics, pp. 111-118, Brussels

Koren, Y., and Ulsoy, A.G. (1997)." Reconfigurable manufacturing systems", Engineering research center for Reconfigurable machining systems (ERC/RMS) Report \# 1, The University of Michigan, Ann Arbor

Koren, Y., Hu, S.J.,Weber, T.W. (1998). Impact of manufacturing system configuration on performance, CIRP Annals, Vol. 47, No.1, pp. 369-372

Koren, Y., (1999). Reconfigurable manufacturing systems, Annals of the CIRP, Vol.48, No.2, pp. 527-540

Koren, Y., (2005). What are the differences between FMS \& RMS, Paradigms of manufacturing- a panel discussion, 3rd Conference on reconfigurable manufacturing, Ann Arbor, Michigan, USA

Koren, Y. ( 2013). The rapid responsiveness of RMS, International Journal of Production Research, Vol.51, No. 23-24, pp. 6817-6827

Mehrabi, M.G., Ulsoy, K. (2000). Reconfigurable manufacturing systems: key to future manufacturing. Journal of Intelligent Manufacturing, Vol.11, pp. 403-419

Mehrabi, M.G., Ulsoy, A.G., Koren, Y., Heytler, P. (2002). Trends and perspectives in flexible and reconfigurable manufacturing systems, Journal of Intelligent Manufacturing, Vol. 13,pp. 135-146

Mittal, K. K. , Jain, P. K. (2014). An Overview of Performance Measures in Reconfigurable Manufacturing System, Procedia Engineering Vol.69, pp. 1125 1129

Yigit, A. S. , Allahverdi, A. (2003). Optimal selection of module instances for modular products in reconfigurable manufacturing systems, int. j. prod. res. Vol.41, No.17, pp. 4063-4074

Youssef, A.M.A., ElMaraghy, H.A. (2006). Assessment of manufacturing systems reconfiguration smoothness, International Journal of Advance Manufacturing Technology, Vol. 30, No. 1-2, pp. 174-193

Youssef, A.M.A., ElMaraghy, H.A. (2007). optimal configuration selection for Reconfigurable Manufacturing. International Journal of Flexible Manufacturing System, Vol. 19, pp. 67-106 